Ross, J. A. (1994). The impact of an in-service to promote cooperative learning on the stability of teacher efficacy. Teaching and Teacher Education, 10 (4), 381-394.

The Impact of an In-service to Promote Cooperative Learning

On the Stability of Teacher Efficacy

John A. Ross*

The Ontario Institute for Studies in Education,

Trent Valley Centre

September 1993 


\begin{abstract}
Teacher efficacy, the extent to which teachers believe they will be able to perform the actions that promote learning, is a key variable predicting teacher practice and student outcomes. Few studies of the stability of professional efficacy have been conducted. This inquiry measured teacher efficacy on three occasions during an eight month in-service. The study found that it was use of in-service knowledge, not exposure to it, that contributed to changes in teacher efficacy and that it was general, not personal teaching efficacy that changed. Interactions among participants persuaded teachers that it was possible for cooperative learning techniques to reach students disadvantaged by home conditions (general teaching efficacy). Any increment in personal confidence (personal teaching efficacy) that might have arisen due to increased teaching skill in the program was offset by increased standards arising from social comparisons among teachers. Teacher changes were related to student outcomes, although not in the expected direction.
\end{abstract}




\section{The Impact of an In-service to Promote Cooperative Learning On the Stability of Teacher Efficacy ${ }^{1}$}

Teacher efficacy, teachers' expectations about their ability to perform the actions required to bring about student learning, is increasingly recognized as a pivotal variable influencing teacher practice and student outcomes. To date there have been very few attempts to increase teacher efficacy through district-organized professional development. This article reports the results of an effort to stimulate teacher efficacy by providing an in-service opportunity for teachers to increase their knowledge and skill of cooperative learning techniques.

\section{Research in Teacher Efficacy}

The concept of teacher efficacy comes from Bandura's $(1977,1986)$ theory of self-efficacy. Self-efficacy can be distinguished from two related constructs: locus of control (Rotter, 1966) which speaks to a subject's beliefs about the degree to which the perceived causes of the intended outcomes are within his/her influence, and outcome expectancy (Schunk, 1984) which describes beliefs about the specific actions that are expected to lead to the preferred results ("whether doing $x$ will lead to $y$ "). Self-efficacy refers to a subject's expectation that he or she will be able to perform the actions required to bring about desired outcomes ("whether I can do $x ")$. In Bandura's account, self-efficacy is a relatively stable constellation of personal beliefs that emerges from a subject's interpretation of experience. Reflection on past successes and failures leads the individual to foresee how well he will be able to perform particular tasks in specific contexts. These anticipations influence willingness to engage in the tasks, the amount of effort expended, and persistence in the face of adversity.

Teacher efficacy is a subcategory of self-efficacy; it refers to an individual's beliefs about proficiency in performing the actions thought to lead to student learning. Although some researchers (e.g., Evans \& Tribble, 1986; Greenwood, Olejnik \& Parkay, 1990) continue to treat teacher efficacy as a uni-dimensional construct, the prevailing view (see, for example, the argument in Woolfolk \& Hoy, 1990) is that there are two theoretically and 
empirically distinct dimensions of professional efficacy: Personal teaching efficacy is a teacher's expectation that he or she will be able to perform the actions that lead to student learning; general teaching efficacy is the belief that the teacher population's ability to perform these actions is limited by factors beyond school control.

Although a variety of measures of teacher efficacy have been developed, many unique to a single study, two instruments have been used so frequently that they are recognized as standard measures. There is extensive evidence for the reliability and validity of each. The Rand studies (Berman, McLaughlin, Bass, Pauly \& Zellman, 1977) developed single items for personal ("If I try really hard I can get through to even the most difficult or unmotivated students.") and general teaching efficacy ("When it comes right down to it, a teacher really can't do much because most of a student's motivation and performance depends on his or her home environment."). Gibson and Dembo (1984) created a larger set of items similar to the Rand measures, using factor analysis to select a nineitem personal and a seven-item general teaching efficacy scale.

Previous research has demonstrated that higher teacher efficacy is associated with the use of teaching techniques which are more challenging and difficult, such as small group techniques (Tracs \& Gibson, 1986), cooperative learning (Wax \& Dutton, 1991), and activity based methods (Riggs \& Enochs, 1990). There is also evidence that teachers with higher efficacy scores are more willing and likely to implement innovative programs (Guskey, 1988; Ross, 1992; Smylie, 1988). These findings suggest that feelings of efficacy provide teachers with the confidence to take the risk of learning difficult professional procedures and to persist with them through the implementation dip. But previous research on this issue has been almost exclusively correlational. In the absence of interventions it is difficult to tell whether teacher efficacy is a cause or a consequence of the adoption of more powerful teaching techniques.

The findings about the impact of teacher efficacy on students are consistent. Personal teaching efficacy contributes to student achievement in curriculum domains involving language, such as reading, language arts and social studies (Anderson, Greene \& Loewen, 1988; Ashton \& Webb, 1986; Ross, 1992; Tracs \& Gibson, 1986). General teaching efficacy contributes to student achievement in math (Ashton \& Webb, 1986; Moore \& Esselman, 1992; Ross \& Cousins, in press). There is also evidence linking teacher efficacy to students' affective growth. 
Higher teacher efficacy is associated with enhanced student motivation (Midgley, Feldlaufer \& Eccles, 1989), increased self-esteem (Borton, 1991), improved self-direction (Rose \& Medway, 1981) and more positive attitudes toward school (Miskel, McDonald \& Bloom, 1983). A variety of explanations for these findings have been proposed. Raudenbush, Rowen, and Cheong (1992) suggested that feelings of professional efficacy might produce a "generative capability" that enables teachers to construct new teaching strategies and increase their level of effort in difficult instructional settings. Since higher efficacy teachers use classroom management approaches that stimulate student autonomy and reduce custodial control, student achievement might be higher because these management strategies are more effective in keeping students on task (Woolfolk, Rosoff \& Hoy, 1990). Higher efficacy teachers may be more successful because they attend to the needs of lower ability students more closely (Ashton, Webb \& Doda, 1983). Finally, teacher efficacy may lead to specific changes in teacher behavior affecting students' perceptions of their academic abilities. As student efficacy becomes stronger they may become more enthusiastic about school work and more willing to initiate contacts with the teacher, processes that impact directly on achievement (Ashton et al., 1983; Ashton \& Webb, 1986).

\section{Stability of Teacher Efficacy}

Ross (1993a), in a review of 64 studies, found that most investigators measured teacher efficacy on a single occasion, treating the construct as it were an immutable trait. Six developmental studies tracked teacher efficacy over relatively short periods of time (the longest was only a year).

There is consistent evidence of substantial change during the preservice period. Hoy and Woolfolk (1990) examined the expectancies of preservice teachers before and after their first practice teaching episodes. The researchers found that personal teaching efficacy scores increased, while general teaching efficacy scores declined. In contrast there were no changes during the same time period in two control samples: preservice teachers who were scheduled to begin their teaching practicum later in the year and undergraduate psychology majors not enrolled in the teacher education program. Hoy and Woolfolk concluded that the beginning teachers became more confident about their own ability to be effective by learning to maintain classroom order. At the same time they 
may have become increasingly willing, as a self-defense mechanism, to attribute their failures to deficiencies in the homes of a few unruly students.

Housego (1990), in an evaluation of a revision of the teacher education program at the University of British Columbia, compared the total teacher efficacy scores of two cohorts of preservice students. The first cohort experienced a decline in feelings of preparedness to teach during the first term of a program combining course work with a teaching practicum. The second cohort's efficacy scores increased during the same period a year later. Although the study design was exposed to internal validity threats (particularly history and differential selection), the evidence is persuasive that the goal of the program revision, increasing students' feelings that they were prepared to teach, had the intended effect. It also confirmed that the practice teaching experience has a substantial impact on teacher expectancies.

Housego (1992) continued this line of research by measuring beliefs about efficacy of a sample of preservice secondary teachers on four occasions over a year. The standard measure (Gibson \& Dembo, 1984) found that personal teaching efficacy increased and general teaching efficacy declined in the first term (September to December), confirming the findings of Hoy and Woolfolk (1990). There were no other changes in succeeding administrations. The non-standard measure, a revision of the "feelings of preparedness to teach" scale developed in Housego (1990), recorded increases in the first (September to December) and second (January to May) terms, with stability thereafter. This time series design suffered from sample attrition (particularly from the base to the end of the first term measurement) but the overall direction of the findings is clear: the preservice period of learning to teach is marked by major changes in teacher efficacy.

In contrast with this picture of rapid change on entry to the profession, teacher efficacy appears to be more stable for experienced teachers. Anderson et al. (1988) used the Gibson and Dembo (1984) instruments to measure the personal and general teaching efficacy of a small, purposeful sample of experienced grade 3 and grade 6 teachers. Twelve teachers with high personal teaching efficacy scores and the same number with low scores were selected. The researchers found that the end of the year results were highly correlated with the scores at the beginning of the year ( $\mathrm{r}=.73$ for personal and .86 for general teaching efficacy). There were no differences in the 
means. Similar results were obtained by Moore and Esselman (1992) in a study of seven experienced elementary teachers assigned to magnet schools. When the beginning and end of year scores were compared, there were no differences in the mean teacher efficacy scores (using the Rand measures). Because the instruments were completed anonymously, Moore and Esselman were unable to correlate the scores.

A third study of experienced teachers found that the efficacy beliefs of a small sample of K-4 teachers $(\underline{N}$ $=14$ ) increased over a year in response to an in-service program. Stein and Wang (1988) measured personal teacher efficacy and teacher practices in implementing a mainstreaming program. The investigators found that implementation increased between fall and winter while teacher efficacy increased from winter to spring. Stein and Wang concluded that it was the increasing expertise of the teachers that led to elevated perceptions of their self-efficacy. A further analysis found that the three highest implementors showed the greatest increase in teacher efficacy, while the efficacy of the three lowest implementors actually declined. The generalizability of the study was weakened by the use of a non-standard measure of efficacy and by the small number of subjects.

Cross-sectional studies shed additional light on the stability of teacher efficacy over time. Beady and Hansell (1981) found that general teaching efficacy declined slightly with years of experience $(\underline{\mathrm{r}}=-.12, \underline{\mathrm{N}}=441)$; Hoy and Woolfolk (1993) had similar findings $(\underline{\mathrm{r}}=-.23, \underline{\mathrm{N}}=179)$. Dembo and Gibson (1985) reported that preservice teachers had the highest confidence in the ability of schools to overcome the disadvantages of children's homes and that general teaching efficacy declined with experience. The correlation again was low. Brousseau, Book and Byers (1988) found that preservice teachers had higher general teaching efficacy than experienced teachers. They also reported that general teaching efficacy was higher among preservice candidates who had experienced practice teaching than among those who had not. Finally, Brousseau et al. found no differences between those with ten years, and less than ten years, experience.

Most of the cross-sectional studies examining the influence of experience on personal teaching efficacy found no significant differences (Guskey \& Passero, 1993; Korevaar, 1990; Midgley, Feldlaufer \& Eccles, 1988; Miskel et al., 1983; Parkay, Olejnik \& Proller, 1988; Rose \& Medway, 1981; Woolfolk et al., 1990). There were two exceptions. Personal teaching efficacy increased in the first few years of teaching in Dembo and Gibson's 
(1985) study and Hoy and Woolfolk (1993) found a small positive correlation between experience and personal teaching efficacy.

The cross-sectional research tends to confirm the findings from the developmental investigations: rapid change in the preservice period, particularly during the first practice teaching episodes, leading to enhanced personal teaching efficacy and reduced general teaching efficacy. Much greater stability is characteristic of experienced teachers.

\section{Research Questions}

The only reported attempt to increase teacher efficacy through in-service (Stein \& Wang, 1988) was successful. But can this promising result be generalized to other curriculum contexts? The study involved a very small number of subjects and it measured effects with a non-standard measure specific to a particular innovation. The purpose of the research reported in this article was to explore the generalizability of the Stein and Wang findings by examining the impact of an in-service program designed to provide teachers with the knowledge and skill to implement cooperative learning techniques. The context for the in-service was a government plan (the Transition Years initiatives) to increase equity in schools in the Intermediate Division by, among other things, eliminating ability tracking in grade 9 (Ontario Ministry of Education, 1992). Teachers, particularly in the secondary panel, reacted negatively to the coming innovation and expressed deep concern about their ability to meet the requirements of the policy. While some took exception to the educational basis for the change, the strongest concerns were associated with the Ministry's hurried approach to implementation which gave insufficient regard to the need to develop teachers' skills. The in-service was designed to help teachers acquire cooperative learning teaching skills that would ease the strain of teaching classes with a broad span of abilities.

Bandura's (1977) theory identifies three sources of information about self-efficacy that might be available to teachers engaged in a professional development program. First, and most important, is knowledge about one's actual performance. If the in-service provides structured opportunities for teachers to practice the skills and apply the knowledge in their own schools, and if they do so successfully, personal teaching efficacy might increase. Second, efficacy is affected by information about the experiences of others. If the in-service provides a forum for 
teachers to experience vicariously the successes of others, general teaching efficacy might be strengthened. Third, if there are occasions in which teachers with experience in the innovation persuade newcomers that they are acquiring the target skills and that they are capable of implementing it successfully, personal teaching efficacy might be enhanced. The in-service might also contribute to greater efficacy indirectly. For example, the in-service might provide needed resources (lesson plans, teaching techniques, assessment devices), and create a social network to support implementation, thereby removing some of the constraints that might limit the success of classroom applications. Or the in-service might influence teachers' perception of the value of the innovation, thereby affecting their interpretations of instructional experiments as successes or failures.

The research addressed three questions.

1. Will experienced teachers become more confident about their ability to meet students' needs over the course of the in-service? It was predicted, on the basis of the Stein and Wang (1988) findings, and Bandura's theory, that personal teaching efficacy scores would increase as teachers acquired skills for coping with mixed ability classes.

2. Will experienced teachers become more confident about the ability of schools to teach all children, regardless of ability and background, over the course of the in-service? No previous research has been conducted on this question. It was predicted from Bandura's theory that general teaching efficacy would increase if teachers became familiar with the successes of their peers.

3. Will changes in teacher efficacy be related to student outcomes? Although no previous study has investigated this question, a study which examined the impact on students of between-teacher changes in efficacy may be relevant. Midgely et al (1989) followed a large cohort of students $(\underline{N}=1,329)$ as they made the transition from grade 6 to grade 7 . The findings showed that students lowered their expectations about future performance and their beliefs about current success if they moved from a high to a low efficacy teacher. Extrapolating from Midgely et al., it was hypothesized that changes in teacher efficacy would be positively correlated with student outcomes. Since the in-service included teachers from a broad array of subject areas and grades, the student outcome measure chosen for the study was a generic one: student attitudes toward giving and seeking help from 
peers. (The rationale for selecting student helpfulness as a measure of cooperative learning is elaborated in Ross \& Cousins, 1993b.) It was predicted that student attitudes would improve to a greater degree in the classrooms of teachers who became more confident about their own effectiveness and that of their peers.

\section{Method}

\section{Subjects}

Subjects were grades 7, 8 and 9 teachers $(\underline{\mathrm{N}}=50)$ from four school districts who volunteered to participate in an in-service program on cooperative learning. The teachers were experienced $(\underline{M}=11.89$ years, $\underline{\mathrm{SD}}=7.35)$; $70 \%$ were in the elementary panel; $58 \%$ were female. Each teacher identified one class in which he or she would introduce cooperative learning techniques ( $\underline{\mathrm{N}}=1,228$ students). A broad range of classes were chosen: English, core French, Geography, Guidance, History, Mathematics, Religion, Science and Social Studies.

\section{Instruments}

Student attitudes toward help giving and help seeking were measured with an instrument adapted from a questionnaire designed by Newman (1990) to measure attitudes to seeking help from the teacher in math class. Seventeen of Newman's items were rewritten so the range of classroom situations were retained, as well as the response options (a five-point scale ranging from "not likely" to "very likely" or "not true of me" to "very true of me"). The specific math context was replaced with "think of a time when you were working in class and had some difficulty with the assignment" and students were asked to think in terms of asking help from peers, rather than the teacher. There were twelve items measuring willingness to seek help from peers (e.g., "How likely are you to ask for help from other students when...you don't understand how to do the assignment?"). There were five items measuring the costs of peer help seeking (e.g., "I feel shy about asking questions of other students."). The help seeking items were rewritten to create a fifteen-item help giving instrument that covered the same range of classroom situations: there were ten items concerning willingness to give help and five items about the cost of giving help. The student attitude items were administered at the beginning and end of the in-service. 
Teacher efficacy was measured on three occasions (at the beginning, mid-point and end of the eightmonth in-service) with a 16-item self-report instrument (Gibson \& Dembo, 1984). Subjects used a six-point agree/disagree scale to respond to statements such as: "When a student does better than usual, many times it is because I exerted a little extra effort." Two scale scores (personal teaching efficacy and general teaching efficacy) were produced. The coding was inverted on six of the items to ensure that high scores meant high efficacy on both scales.

The response of teachers to the in-service was measured at the end of the in-service with three instruments: (a) The Cooperative Learning Self-Appraisal Form was a self-administered questionnaire which probed teachers' decisions regarding why they used student groups, how students were assigned to groups, who takes responsibility for the management of groups and how students are evaluated. There were five response options for each question; the response options corresponded to a profile for cooperative learning implementation adapted from Verhulst (1991). Scores on the four questions were averaged to produce a total score. (b) The Cooperative Learning Telephone Interview was also a self-report measure. It probed the same set of dimensions as the self-administered profile, but the questions were open ended. Respondents were classified into the levels of the profile based on the examples they gave of their classroom strategies. Scores on the four questions were averaged to produce a total score. (c) Overview of Progress was a self-administered survey that was to be completed monthly. Teachers recorded how many times each week they used cooperative learning techniques and the duration of use in minutes. The response rate on this instrument was very low, even when one report was randomly selected from each teacher. In addition, teachers completed a demographic questionnaire.

The qualitative data consisted of: (a) Field notes were made at the site meetings held between plenary sessions (to be described below). Topics of discussion, procedures for making decisions within the site, and teacher beliefs about the successes and failures of the in-service were recorded. At least two meetings were observed in each of the four sites. (b) Documents distributed by teachers at their site meetings were collected. These consisted of shared lesson plans, excerpts from books and journals recommended by teachers, and materials culled from 
other workshops on cooperative learning. (c) Unstructured interviews were conducted with key informants to explore hypotheses about the impact of the sessions.

\section{Treatment}

Activities in the in-service were jointly planned and delivered by an executive committee made up of academics and school practitioners (curriculum consultants for each of the participating school districts), who also served as site leaders. Three plenary sessions (each 150 minutes long) were held. Local planning meetings of varying lengths (most were 120 minutes) took place in each school district approximately monthly from October to May. All sessions were held after school with a meal break. The first plenary session was primarily concerned with influencing the goals of participants. Teachers described why they volunteered for the in-service, they engaged in an activity in which they set personal goals and exchanged their lists with colleagues. Research evidence about the effects of implementing cooperative learning techniques was presented in a large group setting and experienced teachers provided testimonials in smaller gatherings. An overview (based on Clarke, Wideman \& Eadie, 1990) of specific techniques for assigning students to groups, creating interdependence, developing reward structures, and stimulating student talk was presented in a large group format. The first session ended with site planning meetings in which participants developed an organizational structure for local planning and developed a schedule to experiment with cooperative learning methods in their own classrooms.

The second plenary session began with a summary showing similarities among the personal learning goals that had been identified by individuals in the previous session. Teachers, in pairs, were asked to identify student small group behaviors which would be likely to lead to learning and to give a rationale for each selection. These responses were used to sequence a large group lecture/discussion on research on student talk (based on Webb, 1989). Teaching strategies for promoting high quality interactions among students were described and illustrated. For example, it was recommended that teachers provide cooperative tasks that consist of students rehearsing the main ideas of a lesson, illustrating the suggestion with a technique (MURDER) for summarizing text material developed by Dansereau and colleagues (O'Donnell \& Dansereau, 1992). Applications of cooperative 
learning skills to the world of work were addressed through small group discussion of a video. The session ended with a local planning meeting in which teachers scheduled on-site practice of the methods described in the session.

The third plenary consisted of input on teaching strategies that promote the frequency and quality of student explanations (based on Ross \& Cousins, 1993a). Transcripts made from audio recordings of students working in groups to solve math problems were used to illustrate effective and ineffective explanation giving. Techniques for improving the quality of student explanations were described and illustrated. For example, the recommendation that teachers provide students with models of good explanations was illustrated with skits (in written form) developed by Swing and Peterson (1982). The remainder of the session was devoted to teacher presentations of successful experiences and plans for follow up, each conducted in small groups.

The local planning sessions consisted of each group identifying specific issues (such as classroom management or evaluation of group processes) to be investigated by volunteers from the group or by the site leader. At least one teacher presentation describing successful cooperative learning teaching experiences was held in each site session. The agenda for these sessions was set by the teachers with the assistance of each site leader who was a member of the in-service planning committee.

\section{Procedure}

Teacher volunteers were obtained by contacting curriculum superintendents in four school districts; they gave project information to principals who shared it with teachers. Although financial support was obtained from the districts (for meals at the plenary session and for reading materials distributed to teachers), there was minimal involvement of school administrators. Teachers participated in the project as individuals. Prior to the first session (early October), teachers completed the teacher efficacy survey and demographic questionnaire while administering the pretest attitude surveys to one class of their students. After attending the first and second plenary sessions, the teacher efficacy survey was re-administered (February). Overview of progress forms were completed each month. Secondary teachers in semestered schools administered the student post-attitude survey. After the third plenary (May) teachers completed the third teacher efficacy survey, the Cooperative Learning Self-Appraisal and the 
telephone interview. Student post-attitude surveys were administered by teachers in elementary and nonsemestered schools.

\section{Analysis}

A series of exploratory factor analyses with varimax and oblique rotations were conducted on the pretest student attitude items. Student attitude scores for pre- and post-tests were aggregated to the class level and integrated with the teacher data. Descriptive statistics (means, reliabilities) and correlations were compiled for all variables. T-tests were conducted to determine if teachers or students differed by school type (elementary versus secondary.) When calculating correlations with other variables, changes in teacher efficacy scores over the duration of the program were represented as the residual variance remaining from the regression of posttest over pretest scores. Changes in student attitudes were represented in the same way. The effect of the in-service on teacher efficacy was determined by observing changes in means across the three test occasions using a repeated measures analysis of variance. The effect on student attitudes was measured with t-tests. All data analyses were run on SPSSpc.

\section{Results}

There were no differences between elementary and secondary classes on any of the teacher or student variables (t-tests not shown). Consequently the whole sample was used in all analyses.

The teacher variables are described in Table 1. The reliabilities of the scale scores were adequate for personal teaching efficacy. The reliabilities for general teaching efficacy were lower, but were still within an acceptable range. The self-appraisal form and interview profile were internally consistent and reasonably well correlated $(\underline{\mathrm{r}}=.51, \underline{\mathrm{n}}=36, \underline{\mathrm{p}}<.001)$.

\section{Table 1 About Here}

Correlations of efficacy scores over time are displayed in Table 2. The correlations between personal and general teaching efficacy were much higher than have been reported in previous studies using the Gibson \& Dembo (1984) instrument; in the typical study the correlation between them is in the .20 range (see, for example, Ross, 1992). The data in Tables 1 and 2 show that the personal and general teaching efficacy scores of 
experienced teachers in this sample were quite stable. Table 1 shows there was a slight increase for personal teaching efficacy over the three time periods, but the trend was not statistically significant $\underline{\mathrm{F}}(2,54)=2.76, \underline{\mathrm{p}}<.072$. There were no significant changes in general teaching efficacy scores $\underline{F}(2,52)=1.29, \underline{p}<285$. Table 2 shows that the correlations between testing periods were moderate to high. These data suggest that the in-service program had minimal effect on teacher's confidence in responding to the challenges of restructuring.

\section{Table 2 About Here}

The best results from the factor analysis of student attitude items were obtained when the help seeking and help giving items were treated separately. For each set a principal components analysis with varimax rotation produced two factors. Twelve items loaded at least .30 on the willingness to seek help scale (eigen value 4.28) and below .30 on the other factor. Five items loaded at least .60 on the perceived costs of seeking help scale (eigen value 2.50); all of these loaded less than .30 on the other factor. The alpha reliabilities for the two help seeking scales were .82 and .74 . Ten items loaded at .40 or more on the perceived benefits of help giving factor (eigen value 4.60); all loaded below .30 on the other scale. Five items loaded at least .40 on the perceived costs of giving help scale (eigen value 1.76). One of these items also loaded on the other scale (-.40). The alpha reliabilities for the two help giving scales were .84 and .56. Deleting the item that loaded on both scales would have had only a marginal impact on the reliability of the perceived costs scale so the item was retained.

Table 3 displays the student attitude scores for pre- and post-tests. Although all the comparisons were in the expected direction (willingness to seek and give help increased while sensitivity to the cost of help seeking and help giving decreased), only the change in willingness to seek help was statistically significant. These data suggest that the teacher in-service program had only a modest impact on students.

Table 3 About Here

Table 4 correlates changes in teacher efficacy with teacher use of in-service recommendations. Time 1-2 refers to the changes in teacher efficacy scores between the early October and February administrations; change is expressed as the residual variance remaining after February scores were regressed over October scores. Time 1-3 refers to the changes from October to May. The general teaching efficacy correlations show that teachers who 
made greater use of in-service knowledge were more likely to change their beliefs about the ability of teachers to perform the actions that would enable schools to overcome the handicaps of the child's home environment. The correlations of in-service knowledge use and changes in personal teaching efficacy were not significant. Teachers who used the in-service to a greater degree did not change their expectations about their individual effectiveness any more than teachers who made less use of it. There were no significant relationships between changes in personal and changes in general teaching efficacy; correlations ranged from .12 to .28 (not shown).

\section{Table 4 About Here}

Table 5 investigates the influence of teacher efficacy on changes in student attitudes toward helpfulness, represented as the residuals resulting from regressing posttest attitudes over pretest scores. The table shows that there was an association between one of the student outcomes and change in both personal and general teaching efficacy. But the student attitude change was not in the expected direction. Students in the classrooms of teachers who came to feel more efficacious became more conscious of the cost of giving and seeking help.

\section{Table 5 About Here}

\section{Discussion}

Questions 1 and 2 concerned the impact of in-service on teacher efficacy. The main findings were that it was the use of in-service knowledge, not exposure to it, that contributed to changes in teacher efficacy and that it was general, not personal teaching efficacy that changed.

The structure of the in-service provides one explanation

why general, but not personal, teaching efficacy changed. Each of the site sessions and one of the plenaries had a substantial segment devoted to teachers celebrating individual successes. In all sites a relatively small number of teachers, the majority of whom had prior experience in cooperative learning, did the sharing. This procedure may have convinced the remaining teachers that cooperative learning techniques have the potential to change student behaviour, thereby contributing to higher general teaching efficacy scores, as predicted by Bandura's theory about the effect of vicarious experiences. At the same time these expert teachers may have presented a high standard of performance in an atmosphere that promoted social comparisons. Many teachers may have felt they were not 
meeting the new norm, even if they were feeling more competent in using cooperative learning strategies after the in-service. Hence any increase in personal teaching efficacy occurring through increased skill may have been hidden by changes in the definition of what constitutes good teaching.

The staff development program was too weak to bring about changes in personal teaching efficacy. Not only was the duration (eight months) relatively short but the opportunities for teachers to acquire the needed technical knowledge were limited. The plenary sessions emphasized changes in teaching goals and knowledge about how to operationalize these goals, but there were no within-session opportunities to practice teaching skills. Little (1984) found that in-service programs were more successful when they used workshop time for application activities rather than discussion. The self-directed classroom application component failed to provide novices with a residue of successful experiences, possibly because the technical knowledge acquired in the plenaries was insufficient, and/or because there was not enough opportunity for feedback. Yeany and Padilla (1986), in a review of 24 studies of the effects of science in-service, found that programs that arranged for peer or supervisory feedback on classroom practice were three times as effective as those which did not. Other research has found that reciprocal feedback among teachers has a substantial impact on implementation (Fullan \& Stiegelbauer, 1991; Little, 1990). The relatively short duration of the in-service may have been an additional factor inhibiting the development of teaching skills. These weaknesses in the in-service program deprived participants of two sources of information (knowledge of successful personal performance and persuasion by others that teachers were able to perform the desired actions) that might have increased personal teaching efficacy in a more powerful treatment. The specific context of the study may have contributed to change in general teaching efficacy. The Transition Years initiative (as a whole) was a compensatory program. The rationale for its promulgation was social equity: the public statements of the education minister of the day invariably touted the benefits of the reform for disadvantaged groups. Teachers shared this belief, although many did not support the policy, arguing that the purported benefits for the socially disadvantaged would be secured at the expense of high achievers. As the project progressed the belief that cooperative learning would have the effect of reducing the gap between those advantaged 
or disadvantaged by their home backgrounds grew among those who were engaged by the in-service, contributing to changes in general teaching efficacy.

The finding that teacher efficacy scores tended to be relatively stable over the course of the in-service confirms previous research. It may be that change in teacher efficacy occurs rapidly in the early years of teaching as teachers crystallize their professional identity; once consolidated this identity may persist into later years. This is not to suggest that teacher efficacy is obdurate. But to change it in a material way likely takes something more substantial (e.g., a dramatic shift in teaching assignment that often comes with a change of school or an involuntary alteration of curriculum) than a routine in-service program of the type implemented in this study.

With regard to the third research question, changes in teacher efficacy did have an impact on changes in student attitudes toward helping one another learn. But the finding was not in the direction predicted at the outset of the study. Students taught by teachers who changed the most became more conscious of the costs of helping, not less so. This finding may indicate that as the in-service progressed teachers who felt more confident about the overall worth of cooperative learning and of their competence with these methods became more willing to increase the demands on student groups to take responsibility for their own learning. Teachers in the site sessions frequently reported that many of the more able students in their classes expressed concern that giving help to the less able retarded the progress of the most capable students by slowing the pace and creating new tasks for them. These concerns could have led to increased scores in the costs of giving help scale. Increased sensitivity to the cost of seeking help may have resulted from a similar process. Newman \& Goldin (1990) found that peer ridicule is the most significant impediment to help seeking; they also discovered that the inhibition can be overcome if students can be persuaded that asking for help will contribute to their learning. Some students may have found they were exposed to increased peer appraisal without gaining useful assistance. This could lead to changes in the perceived costs of seeking help scores of students taught by teachers who increased their expectations. It is also possible, particularly since the correlations in Table 5 were so low, that poor implementation of the teaching strategies might account for the unexpected findings. 
The findings from this study suggest several directions for further research. First, we need more studies examining the impact of in-service programs on teacher efficacy. The most important requirement is that more powerful treatments be employed. As discussed earlier, teacher efficacy is more likely to be enhanced if teachers experience successful applications of the target skills and if there is supportive feedback. These factors suggest that in-service programs that make greater use of school culture variables, particularly those which simultaneously strengthen collaboration among teachers while introducing new teaching ideas, are more likely to affect teacher efficacy. Several researchers have found that engagement in joint work (such as lesson preparation) contribute to higher teaching efficacy (Miskel et al., 1983; Rosenholtz, 1989; Ross, 1992). The relationship between efficacy and collaboration may be reciprocal; as teachers work together they may persuade each of other of their competence, increasing teacher efficacy, which may in turn stimulate further collegial interaction since persistence and risk taking are associated with higher efficacy. Future research on the effects of in-service needs to give careful attention to other organizational variables that might mediate the impact on efficacy. For example, leadership actions, such as teacher perceptions of efforts made by principals on their behalf (Hoy \& Woolfolk, 1993), involving teachers in school decision making (McLaughlin \& Marsh, 1978; Moore \& Esselman, 1992), and increasing teachers' certainty about the worth of their practice (Smylie, 1988), have been associated with heightened levels of teacher efficacy. There is also evidence that other school characteristics, such as high student achievement (Smylie, 1988), drawing upon high socio-economic status neighbourhoods (Hoover-Dempsey et al., 1987) and reduced stress (Greenwood, et al., 1990; Hall, et al., 1992), influence teacher efficacy and may therefore interact with the impact of in-service.

Disentangling the provision of in-service from other organizational factors is likely to be complex. The strategy used in the majority of teacher efficacy studies to date has been to deal with these complexities through rigorous path analytic techniques requiring large samples. In this approach the measurement of key constructs is often based on severely limited indicators. An alternate tactic might be to adopt a qualitative stance and collect rich descriptive data that would enable researchers to assess the impact of in-service on efficacy in the context of other organizational initiatives and conditions. Such an approach would also permit collection of observational 
data, rather than relying upon self-report measures as in the research reported here. Previous research demonstrates that teacher self-reports are often distorted by interest bias (Wubbels, Brekelmans, \& Hooymayers, 1992).

Second, we need to continue studies examining within-teacher changes in teacher efficacy. Of particular interest would be inquiries that examine how different classes within a teacher's workload contribute to their beliefs about efficacy. Raudenbush et al. (1992) have made a promising start by finding that $44 \%$ of the variance in personal teacher efficacy is attributable to within-teacher factors, such as how well prepared the teacher feels in teaching a particular class, its academic track, grade, size, and level of student engagement. It may be that these class characteristics, and others yet to be determined, mediate the impact of in-service on teacher efficacy. What is especially interesting about these variables is that it may be easier to gain control of them, for example, by making them explicit objectives of in-service sessions, than the organizational mediators described above.

Attending to these within-teacher variables and to the organizational contexts in which teachers work suggests that teacher efficacy researchers are moving toward a greater appreciation of the specificity of the referents of self-efficacy. By being more specific about the tasks teachers feel capable of performing we may need to design new instruments that are focused on specific learning domains, such as the specialized science teaching efficacy instruments of Enochs and colleagues (Riggs \& Enochs, 1990; Rubeck \& Enochs, 1991) or the innovation specific teacher efficacy measures of Stein and Wang (1988). 


\section{REFERENCES}

Anderson, R., Greene, M., \& Loewen, P. (1988). Relationships among teachers' and students' thinking skills, sense of efficacy, and student achievement. Alberta Journal of Educational Research, 34 (2), 148-165.

Ashton, P. \& Webb, R. (1986). Making a difference: Teachers' sense of efficacy and student achievement. New York: Longman.

Ashton, P., Webb, R., \& Doda, N. (1983). A study of teacher's sense of efficacy. Final report to the National Institute of Education, Executive Summary. Gainesville, FL: Florida University. ED 231833

Bandura, A. (1977). Self-efficacy: Toward a unifying theory of behavioral change. Psychological Review, 84, 191-215.

Bandura, A. (1986). Social foundations of thought and action: A social cognitive theory. Englewood Cliffs, NJ: Prentice-Hall.

Beady, C., \& Hansell, S. (1981). Teacher race and expectations for student achievement. American Educational Research Journal, 18 (2), 191-206.

Berman, P., McLaughlin, M., Bass, G., Pauly, E., \& Zellman, G. (1977). Federal programs supporting educational change. Vol. 7. Factors affecting implementation and continuations. Santa Monica, CA: Rand Corporation.

Borton, W. (1991). Empowering teachers and students in a restructuring school: A teacher efficacy interaction model and the effect on reading outcomes. Paper presented at the American Educational Research Association, Chicago.

Brousseau, B., Book, C., \& Byers, J. (1988). Teacher beliefs and the cultures of teaching. Journal of Teacher Education, 39 (6), 33-39.

Clarke, J., Wideman, R., \& Eadie, S. (1990). Together we learn. Toronto: Prentice-Hall.

Dembo, M., \& Gibson, S. (1985). Teachers' sense of efficacy: An important factor in school achievement. The Elementary School Journal, 86 (2), 173-184. 
Evans, E., \& Tribble, M. (1986). Perceived teaching problems, self-efficacy, and commitment to teaching among preservice teachers. Journal of Educational Research, 80 (2), 81-85.

Fullan, M., \& Stiegelbauer, S. (1991). The new meaning of educational change. New York: Teachers College Press.

Gibson, S. \& Dembo, M. (1984). Teacher efficacy: A construct validation. Journal of Educational Psychology, 76 (4), 569-582.

Greenwood, G., Olejnik, S., \& Parkay, F. (1990). Relationships between four teacher efficacy belief patterns and selected teacher characteristics. Journal of Research and Development in Education, 23 (2), 102-107.

Guskey, T. (1988). Teacher efficacy, self-concept, and attitudes toward the implementation of instructional innovation. Teaching and Teacher Education, 4 (1), 63-69.

Guskey, T., \& Passaro, P. (1993). Teacher efficacy: A study of construct dimensions. Paper presented at the annual meeting of the American Educational Research Association, Atlanta.

Hall, B., Burley, W., Villeme, M., \& Brockmeier, L. (1992). An attempt to explicate teacher efficacy beliefs among first year teachers. Paper presented at the annual meeting of the American Educational Research Association, San Francisco.

Hoover-Dempsey, K., Bassler, O., Brissie, J. (1987). Parent involvement: Contributions of teacher efficacy, school socioeconomic status, and other school characteristics. American Educational Research Journal, 24 (3), 417-435.

Housego, B. (1990). A comparative study of student teachers' feelings of preparedness to teach. Alberta Journal of Educational Research, 36 (3), 223-240.

Housego, B. (1992). Monitoring student teachers' feelings of preparedness to teach, personal teaching efficacy, and teaching efficacy in a new secondary teacher education program. Alberta Journal of Educational Research, 38 (1), 49-64.

Hoy, W., \& Woolfolk, A. (1990). Socialization of student teachers. American Educational Research Journal, 27 (2), 279-300. 
Hoy, W., \& Woolfolk, A. (1993). Teachers' sense of efficacy and the organizational health of schools. Elementary School Journal, 93 (4), 355-372.

Korevaar, G. (1990). Secondary school teachers' courses of action in relation to experience and sense of self-efficacy. Paper presented at the annual meeting of the American Educational Research Association, Boston.

Little, J. (1984). Seductive images and organizational realities in professional development. Teachers College Record, 86 (1), 84-102.

Little, J. (1990). Conditions of professional development in secondary schools. In M. McLaughlin, J. Talbert \& N. Bascia (Eds.) The contexts of teaching in secondary schools: Teachers' realities. New York, NY: Teachers College Press, 187-223.

McLaughlin, M., \& Marsh, D. (1978). Staff development and school change. Teachers College Record, 80 (1), 69-94.

Midgley, C., Feldlaufer, H., \& Eccles, J. (1988). The transition to junior high schools: Beliefs of pre- and posttransition teachers. Journal of Youth and Adolescence, 17, 543-562.

Midgley, C., Feldlaufer, H., \& Eccles, J. (1989). Change in teacher efficacy and student self- and task-related beliefs in mathematics during the transition to junior high school. Journal of Educational Psychology, 81 (2), 247-258.

Miskel, C., McDonald, D. \& Bloom, S. (1983). Structural and expectancy linkages within schools and organizational effectiveness. Educational Administration Quarterly, 19 (1), 49-82.

Moore, W., \& Esselman, M. (1992). Teacher efficacy, empowerment, and a focussed instructional climate: Does student achievement benefit? Paper presented at the annual meeting of the American Educational Research Association, San Francisco.

Newman, R. (1990). Children's help-seeking in the classroom: The role of motivational factors and attitudes. Journal of Educational Psychology, 82 (1), 71-80. 
Newman, R., \& Goldin, L. (1990). Children's reluctance to seek help with schoolwork. Journal of Educational Psychology, 82 (1), 92-100.

O'Donnell, A., \& Dansereau, D. (1992). Scripted cooperation in student dyads: A method for analyzing and enhancing academic learning and performance. In R. Hertz-Lazarowitz \& N. Miller (Eds.), Interaction in cooperative groups: The theoretical anatomy of group learning (pp. 120-141), Cambridge, UK: Cambridge University Press.

Ontario Ministry of Education (1992). Policy framework for the transition years. Unpublished draft. Toronto: Queen's Park.

Parkay, F., Olejnik, S., \& Proller, N. (1988). A study of relationships among teacher efficacy, locus of control, and stress. Journal of Research and Development in Education, 21 (4), 13-22.

Raudenbush, S., Rowen, B., Cheong, Y. (1992). Contextual effects on the self-perceived efficacy of high school teachers. Sociology of Education, 65, 150-167.

Riggs, I., \& Enochs, L. (1990). Toward the development of an elementary teacher's science teaching efficacy belief instrument. Science Education, 74 (6), 625-638.

Rose, J., \& Medway, F. (1981). Measurement of teachers' belief in their control over student outcomes. Journal of Educational Research, 74, 185-190.

Ross, J. A. (1992). Teacher efficacy and the effect of coaching on student achievement. Canadian Journal of Education, 17 (1), 51-65.

Ross, J. A. (1993a) Research on teacher efficacy. Unpublished manuscript. Peterborough, ON: OISE Trent Valley Centre.

Ross, J. A., \& Cousins, J. B. (1993b). Explanation seeking as an achievement strategy. Paper presented at the annual meeting of the Canadian Society for the Study of Education, Ottawa.

Ross, J. A., \& Cousins, J. B. (1993c). Self-reports and observed behavior: Seeking and giving help to peers. Paper presented at the annual meeting of the American Educational Research Association, Atlanta. 
Ross, J. A. \& Cousins, J. B. (1993). Enhancing secondary school students' acquisition of correlational reasoning skills. Research in Science \& Technological Education, 11 (3), 191-206.

Rotter, J. (1966). Generalized expectancies for internal versus external control of reinforcement. Psychological Monographs, 80 (1), 1-28. Dissertation Abstracts International, 41, 3496A.

Rubeck, M., \& Enochs, L. (1991). A path analytic model of variables that influence science and chemistry teaching self-efficacy and outcome expectancy in middle school science teachers. Paper presented at the annual meeting of the National Association for Research in Science Teaching, Lake Geneva, WI.

Schunk, D. (1984). Self-efficacy perspective on achievement behavior. Educational Psychologist, 43, 56-67.

Smylie, M. (1988). The enhancement function of staff development: Organizational and psychological antecedents to individual teacher change. American Educational Research Journal, 25 (1), 1-30.

Stein, M., \& Wang, M. (1988). Teacher development and school improvement: The process of teacher change. Teaching and Teacher Education, 4 (2), 171-187.

Swing, S. \& Peterson, P. (1982). The relationship of student ability and small-group interaction to student achievement. American Educational Research Journal, 19 (2), 259-274.

Tracs, S., \& Gibson, S. (1986). Effects of efficacy on academic achievement. Paper presented at the California Research Association annual meeting, Marina del Rey.

Verhulst, D. (1991). An innovation profile. Cooperative Learning, 12 (2), 32-34.

Wax, A., \& Dutton, M. (1991). The relationship between teacher use of cooperative learning and teacher efficacy. Paper presented at the annual meeting of the American Educational Research Association, Chicago.

Webb, N. (1989). Peer interaction and learning in small groups. International Journal of Educational Research, $13(1), 21-39$.

Woolfolk, A., \& Hoy, W. (1990). Prospective teachers' sense of efficacy and beliefs about control. Journal of Educational Psychology, 82 (1), 81-91. 
Woolfolk, A., Rosoff, B., \& Hoy, W. (1990). Teachers' sense of efficacy and their beliefs about managing students. Teaching and Teacher Education, 6 (2), 137-148.

Wubbels, T., Brekelmans, M., \& Hooymayers, H. (1992). Do teacher ideals distort the self-reports of their interpersonal behavior. Teaching and Teacher Education, 8 (1), 47-58.

Yeany, R. \& Padilla, M. (1986). Training science teachers to utilize better teaching strategies: A research synthesis. Journal of Research in Science Teaching, 13 (5), 85-96. 
TABLE 1

Description of Teacher Variables

\begin{tabular}{lcccccc}
\hline \multicolumn{1}{c}{ Variable } & Mean & $\begin{array}{c}\text { Std. } \\
\text { Dev. }\end{array}$ & $\begin{array}{c}\text { Number } \\
\text { of Cases }\end{array}$ & Alpha & $\begin{array}{c}\text { Number } \\
\text { of Items }\end{array}$ & $\begin{array}{c}\text { Range } \\
\text { of Score }\end{array}$ \\
\hline $\begin{array}{l}\text { Teacher Efficacy } \\
\text { personal 1 }\end{array}$ & 4.26 & .38 & 49 & .80 & 9 & $1-6$ \\
-personal 2 & 4.36 & .29 & 40 & .82 & 9 & $1-6$ \\
-personal 3 & 4.43 & .36 & 44 & .78 & 9 & $1-6$ \\
-general 1 & 3.12 & .39 & 50 & .59 & 7 & $1-6$ \\
-general 2 & 3.24 & .31 & 41 & .64 & 7 & $1-6$ \\
-general 3 & 3.10 & .48 & 45 & .75 & 7 & $1-6$ \\
Self Appraisal Survey & 3.32 & .22 & 38 & .59 & 4 & $1-5$ \\
Self Appraisal Telephone & 4.31 & .21 & 48 & .57 & 4 & $1-5$ \\
Number times in month & 12.56 & 6.49 & 25 & - & 1 & $0-\infty$ \\
Number minutes in month & 212.68 & 146.44 & 25 & - & 1 & $0-\infty$ \\
\hline
\end{tabular}


TABLE 2

Correlation of Teacher Efficacy Variables $(\mathrm{N}=31-48)$

\begin{tabular}{rrrrrr}
\hline & \multicolumn{3}{c}{ Personal } & \multicolumn{2}{c}{ General } \\
\cline { 2 - 6 } & Time 1 & Time 2 & Time 3 & Time 1 & Time 2 \\
\hline Personal 1 & - & & & \\
2 & & - & & \\
3 & $.67 * * *$ & $.61^{* * *}$ & - & & \\
General 1 & $.60^{* * *}$ & $.50^{* *}$ & .27 & - & \\
2 & $.45^{* * *}$ & $.33^{*}$ & $.36^{*}$ & $.58^{* * *}$ & - \\
3 & $.49^{* *}$ & $.49^{* *}$ & $.37^{*}$ & $.55^{* * *}$ & $.81^{* * *}$ \\
\hline
\end{tabular}

$* \mathrm{p}<.05 . * * \mathrm{p}<.01 . * * * \mathrm{p}<.001$ 
TABLE 3

Student Attitudes Toward Giving and Seeking Help, Pre \& Post Means and Standard Deviations $(\mathrm{N}=38)$

\begin{tabular}{lcccc}
\hline Student Attitude Scale & Range & Pretest & Posttest & T-test \\
\hline Ask - Willing & $1-5$ & $3.66(.29)$ & $3.90(.25)$ & $\mathrm{t}=-4.97, \mathrm{df}=37, \mathrm{p}<.001$ \\
Ask - Cost & $1-5$ & $2.06(.26)$ & $1.99(.25)$ & $\mathrm{t}=1.85, \mathrm{df}=37, \mathrm{p}<.072$ \\
Give - Willing & $1-5$ & $3.88(.27)$ & $3.93(.29)$ & $\mathrm{t}=-1.36, \mathrm{df}=37, \mathrm{p}<.183$ \\
Give - Cost & $1-5$ & $2.15(.29)$ & $2.07(.18)$ & $\mathrm{t}=1.64, \mathrm{df}=37, \mathrm{p}<.109$ \\
\hline
\end{tabular}


TABLE 4

Correlations of Changes in Teacher Efficacy with In-service Use.

\begin{tabular}{lccccc}
\hline \multirow{2}{*}{ In-Service Use } & \multicolumn{2}{c}{$\begin{array}{c}\text { Personal Teaching } \\
\text { Efficacy Residuals }\end{array}$} & \multicolumn{3}{c}{$\begin{array}{c}\text { General Teaching Efficacy } \\
\text { Residuals }\end{array}$} \\
\cline { 2 - 6 } & Time 1-2 & Time 1-3 & Time 1-2 & Time 1-3 & $\underline{\mathrm{N}}$ \\
\hline Number times in month & .06 & .07 & .42 & $.44^{*}$ & $16-21$ \\
Number minutes in month & .00 & .21 & $.49 *$ & .09 & $16-20$ \\
Self-Appraisal Survey & .27 & .24 & $.39 *$ & $.36^{*}$ & $21-29$ \\
Self-Appraisal Interview & .02 & .26 & $.34 *$ & .25 & $29-35$ \\
\hline
\end{tabular}

$* \mathrm{p}<.05$. 


\section{TABLE 5}

Correlations of Change in Teacher Efficacy with Change in Student Attitudes

\begin{tabular}{lccccc}
\hline \multirow{2}{*}{$\begin{array}{c}\text { Student Attitude } \\
\text { Residuals }\end{array}$} & \multicolumn{4}{c}{$\begin{array}{c}\text { Personal Teaching } \\
\text { Efficacy Residuals }\end{array}$} & $\begin{array}{c}\text { General Teaching Efficacy } \\
\text { Residuals }\end{array}$ \\
\cline { 2 - 6 } & Time 1-2 & Time 1-3 & Time 1-2 & Time 1-3 & \\
\hline Ask - Willing & .02 & -.05 & .06 & .21 & $(\mathrm{n}=25-30)$ \\
Ask - Cost & $.51^{* *}$ & .00 & $.48^{* *}$ & .28 & $(\mathrm{n}=25-30)$ \\
Give - Willing & -.06 & -.05 & .03 & .19 & $(\mathrm{n}=25-30)$ \\
Give - Cost & $.41^{*}$ & .01 & .21 & -.03 & $(\mathrm{n}=25-30)$ \\
\hline
\end{tabular}

${ }^{*} \mathrm{p}<.05 .{ }^{*} * \mathrm{p}<.01$ 


\section{$\underline{\text { Footnotes }}$}

${ }^{1}$ The research was funded by the Ontario Ministry of Education and Training through a grant to the Ontario Institute for Studies in Education and by the Social Sciences and Humanities Research Council of Canada. The views expressed here do not necessarily represent the position of the Ministry or the Council. Anne HogaboamGray and Peter Gray contributed to various aspects of the research. 